\title{
Internet Protocol Television (IPTV) Implication for Education
}

\section{Pannee Suanpang}

Information Technology Department, Faculty of Science \& Technology, Suan Dusit Rajabhat University, Bangkok, Thailand. E-mail: dtechpannee@yahoo.com

Received 2012

\begin{abstract}
This paper illustrates the development of Internet Protocol Television (IPTV) and its implication for education. IPTV is a new type of educational technology that provides digital content (text, graphic, audio and video) which users watch as television broadcasting on the In ternet. With the cap abilities of IPTV th at cou ld be used for edu cational pu rpose. Therefore, the IPTV project's (Suan Dusit Internet Broadcasting: SDIB) aim has bee $\mathrm{n}$ to develop into a pl atform that increase educational opportunities that supp ort distant education. The IPTV system w as designed to broadcast in fo ur channels (kids, video on demand, variety an d rad io). More th an sev en hu ndred program are $b$ eing tran smitted $b$ oth trough live and video on demand streams via computer, set top boxes and mobile devices. The IPTV system has be en implemented and used in 80 pilot schools. The data of an evaluation of the IPTV system was collected from questionnaires and interviews. The results indicated that IPTV users were highly satisfied with the contents, set top boxes, LCD television, and overall IPTV systems.
\end{abstract}

Keywords: IPTV; Internet Broadcasting; Educational Technology

\section{Introduction}

Internet protocol telev ision (IPTV) is a co llection of modern technologies in computing, networking, and storage in tegrated $t o$ delivery d igital con tent thro ugh an Internet Protocol (IP) net work [1]. Thi s system broadcasts va rious types of digital co ntent i ncluding $t$ ext, graphic, audio and video files over an IP network in order to reach a large number of users [2]. IPTV uses digital $\mathrm{b}$ roadcast network su ch as ADSL and satellite to broadcast the data and provide user interface, which can be either a television monitor or web page with a m enu organized i $\mathrm{n}$ s everal cat egories such as $\mathrm{m}$ ovies, vi deo games and radio [3]. The IPTV occurrence is being continuously enhanced with improvements in its underlying networking a nd computing. The successful de ployment of IPTV on a large scale is essentially d ependent on a wide range of supporting technologies $[1,4]$.

IPTV has changed the way of users ' access information, knowledge and entertainment. It has been utilized in multiple sectors such as bus iness, e ntertainment, com munication, healthcare and education. The implication of IPTV for education are becoming admired, especially in supporting distant edu cation. IPTV can provide $\mathrm{m}$ ore collaborative co ntent th an trad itional telev ision app lica- tions and it encourages existing passive television learners to become more actively invol ved in $t$ heir learning activities [5]. However, th ere $h$ as been limited research and a few articles on IPTV's implications for education.

This study breaks new ground and addresses key questions a bout the devel opment of IPTV sy stem im plications for teaching and learning. The aim of this paper is to study the development and deployment of IPTV (Suan Dusit In ternet Bro adcasting: SDIB) and its implications for education.

\subsection{IPTV Trends}

Currently, the IPTV industry has grown enormously both in $t$ erm of $n$ umber of $s$ ubscribers an $d$ i nvestments by service providers. The world's leading markets for IPTV are Germ any, Fran ce (2 .7 millio $\mathrm{n} u$ sers end of 2009), South Korea (1.8 million users), and other [1]. Multimedia Researc h Group is fore casting that the num ber of global IPTV users i $\mathrm{n} 2013$ will g row to 81 million and the service revenue is exp ected to grow to $\$ 19.9$ billion $[6,1]$.

IPTV trends c reate a new model for service provisioning an $\mathrm{d}$ a tran sition from trad itional broadcastercentric telev ision serv ices to a user-centric telev ision 
model. The IP TV u ser's be havior is changing from active to passive and content digitization allows for easier distribution [1]. The ad vances in IPTV tech nology will blend as pects of comm unication, social media, inte ractivity, and search information in new ways. In the future, IPTV is e xpected to cha nge the user experience by enhancing user's interactivity, service personalization (such as c ontent personalization, r ecommendations, t arget a dvertisements, and personalize channels [8], mobility and multi devices/screen usage.

\subsection{IPTV System Capabilities}

The IPTV system capabilities [5,9] shown in Table 1

\subsection{IPTV Architectures}

The basic IPTV architecture shown in Figure 1.

Table 1. IPTV system capabilities.

\begin{tabular}{|c|c|}
\hline Issues & IPTV Capabilities \\
\hline Users & $\begin{array}{l}\text { worldwide that have known IP addresses } \\
\text { and known locations }\end{array}$ \\
\hline Video quality & Controlled QoS, broadcast TV quality \\
\hline Connection bandwidth & Between 1 and $4 \mathrm{Mbit} / \mathrm{s}$ \\
\hline Video format & $\begin{array}{l}\text { MPEG-2 } \\
\text { MPEG-4 Part } 2 \\
\text { MPEG-4 Part (AVC) } \\
\text { Microsoft VC1 }\end{array}$ \\
\hline Receiver device & Set top box with a television display \\
\hline Resolution & Full TV display \\
\hline Reliability & Stable \\
\hline Security & Uers are authentification and protected \\
\hline $\begin{array}{l}\text { Complementarily with } \\
\text { cable, terrestrial and } \\
\text { satellite broadcasting }\end{array}$ & $\begin{array}{l}\text { Potential commenon STB, complementary } \\
\text { coverage, common metadata }\end{array}$ \\
\hline Copyright & Media is protected \\
\hline
\end{tabular}

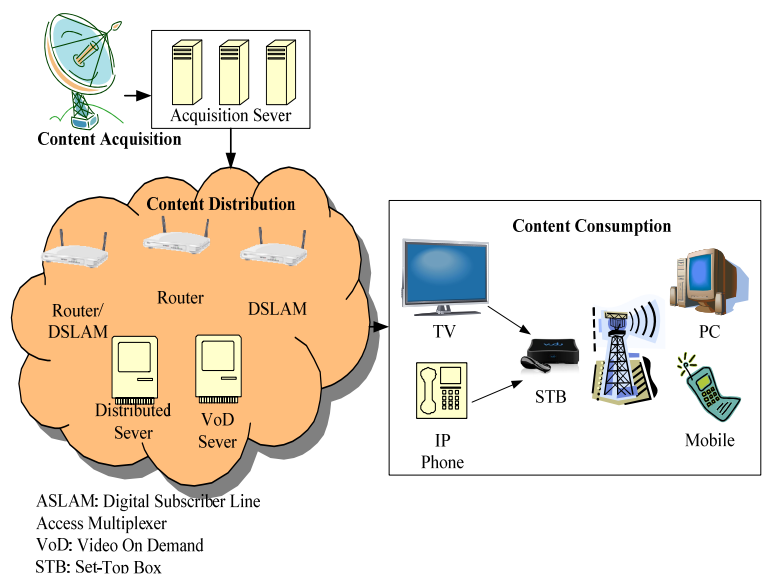

Figure 1. Basic IPTV architectures.
The basic IPTV architecture components include [1]:

1) Acquisition severs (A-sev ers): for en coding video and DRM metadata.

2) Distributed severs (D-Sever): provide caching and QoS control.

3) VoD creat ors a nd severs: retain a libra ry of en coded VoD content to provide VoD services.

4) I P r outers: route IP packets an d provide fast reroute in case of routing failures.

5) R esidential gat eways: IP routers for bundled service at home.

6) STBs: a STB (Set top box) is a de vice on the user side that interfaces wit $\mathrm{h}$ the user terminal (e.g. T V, PC, laptop, and others) with DSL or cable wiring.

\section{IPTV Implication for Education}

The IP V implications for education project was im plemented at Suan Dusit Rajbhat University, Thailand since 2008. The IPT V was called Suan Dusit Int ernet Broadcasting (SDIB).

\subsection{Aims of IPTV}

The aims of IPTV are to develop new educational innovations for supporting distance and life-long learning for students of S uan D usit R ajabhat University and t o i ncrease learning cha nnels for the delivery of in formation and knowledge to local communities [11].

\subsection{Concepts}

IPTV was designed to support education. Figure 2 shows the IPTV system design for support distance learning.

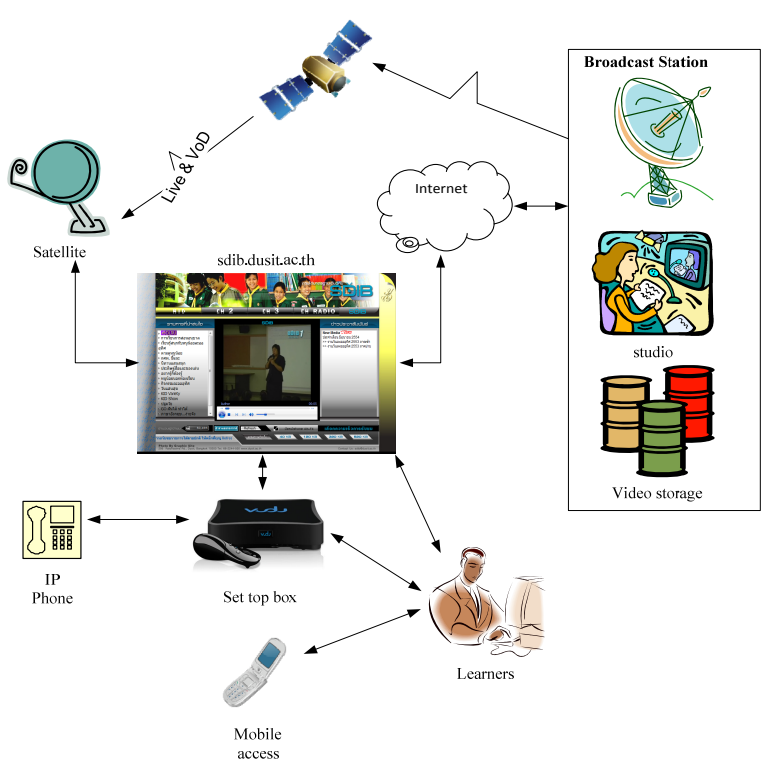

Figure 2. IPTV designed concept. 


\subsection{Channels, Contents and Users}

IPTV was des igned to broadcast in four chan nels and provided the following contents $[2,3,10,11]$ :

- Channel 1 (kid program ): broadcasts teaching a nd learning at Sa-Tid-La-O r-U-Tid prim ary schoo ls. Most of the contents are useful for distance students who are studying in the Bachelor of Education Program in Pre-school Education . C urrently, th e university h as more than 20,000 distance students who are studying in this program. Most of them are teache rs who a re working in the early ch ildhood care centers in Thailand, and $\mathrm{t}$ herefore the cont ents of this c hannel a re useful for $\mathrm{t}$ hem. This channel broa dcast more than 372 programs that focus on early childhood education. There a re $m$ any interesting program such as brainbased learning (BBL), toys for children, and food and nutrition for children. Moreover, there are some live programs such as Ki ndergarten Fantasia which broadcasts ch ildren's activ ities in th eir classro om; p arents can watch these program s from the In ternet. Users who are distance stude nts currently number $m$ ore than 20,000. Furthermore, the audience includes parents, kinde rgarten school teachers, and re searchers who are interested in studying early childhood education.

- Channel 2 (vi deo on dem and of university teaching): broadcasts vi deo on dem and for bachel or's and master's degree st udents. This $\mathrm{c}$ hannel $\mathrm{b}$ roadcasts more than 95 pro grams. Users wi $11 \mathrm{~b}$ e stud ents who are studying at Suan Dusit Rajabhat University, of which there are currently around 30,000.

- Channel 3 (variety): broadcasts variety programs with a fo cus on the un iversity's strengths. Th is ch annel broadcasts more than 240 programs. There are m any interesting prog ram su ch as Food and Thai $\mathrm{Cu}$ isine, Thai Handicrafts, Tourism in Thailand, Thai Food and Beverages, and others. Users will b e students, teachers, university staff, and people who are in terested in these programs.

- Channel 4 (radio): broadcast radio programs for users who ha ve low internet acces $\mathrm{s}$. T his $\mathrm{c}$ hannel broa dcasts 11 programs. There are $\mathrm{m}$ any in teresting programs such as Art of children, Knowledge Management for Fun, and others. Users will be people who have low speeds of internet access.

\subsection{IPTV Architecture}

The IPTV architecture design shows in Figure 3. It consisted of

- Studio rooms for live broadcasting which have high definition video cameras.

- A m ultimedia server (MMS) whi ch se parated o ne channel from one server. Server numbers 1-3 were located in the control room at Sua n Dusit R ajabhat University, Th ailand. Se rver nu mbers 4-5 w ere located at CAT Telecommunication as a co-location.

- SAN storage for 6 terabytes for storing multimedia content.

- F5 as the load balance for distributing traffic to the Intranet.

- Website (s dib.dusit.ac.th) for br oadcasting content through users. Figure 4 shows website of the IPTV.

\subsection{Devices}

Users can access IPTV by using PCs, tablets (iPad, Galaxy Tab, HP Touchpad), smart phones and smart TVs (iPhone, Samsung, B lackBerry, N okia, HTC, S ony Internet TV). The br owser su pported both browsers on PCs (In ternet Explorer, Firefox, Safari, Chrome) and browsers on mobiles (Safari on iOS, Android, Internet Explorer Mobile).

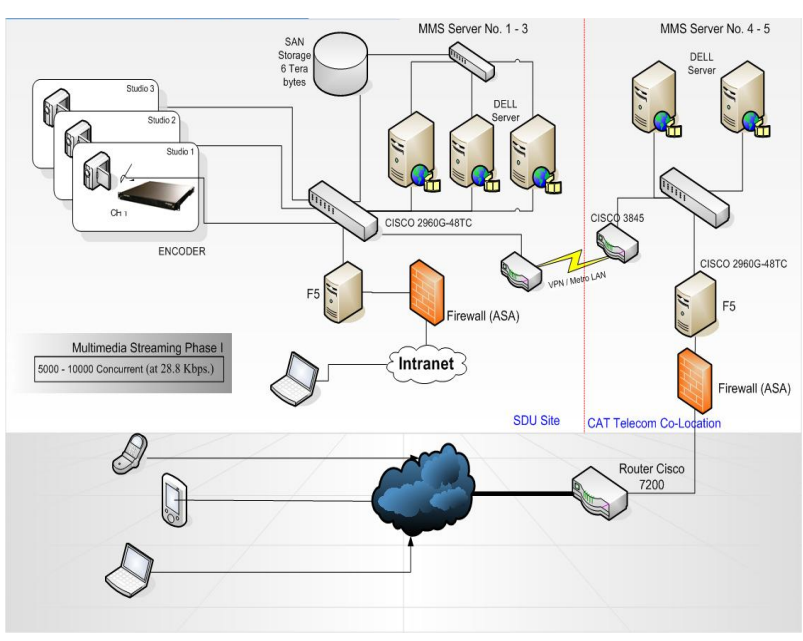

Figure 3. IPTV hardware architecture.

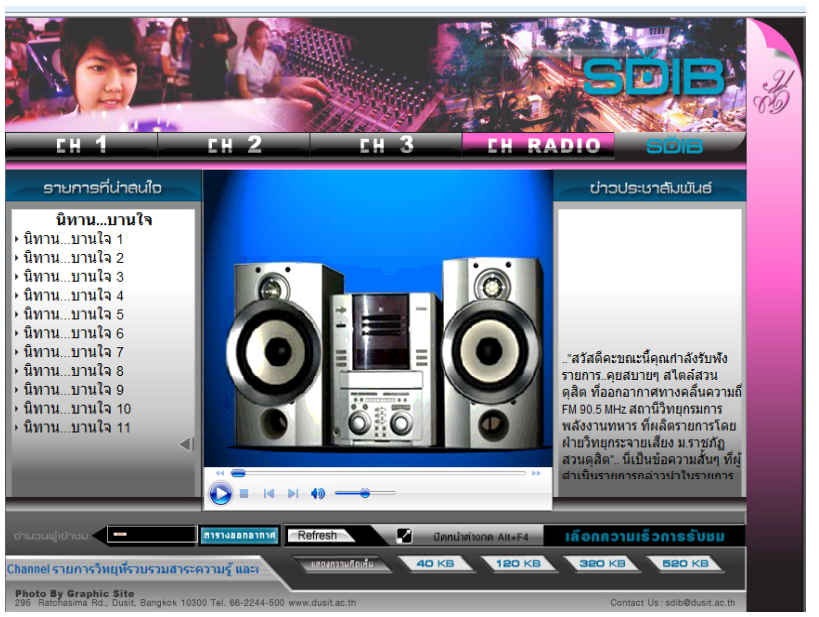

Figure 4. IPTV website. 
The questionnaire was di vided into three parts: demographics i nformation, IPTV sy stem eval uation, and user satisfaction. The questi onnaire trials and had a hi ghly reliability (Alpha Coefficient by Cronbach) of 0.988 .

\section{Result}

The demographics profile of IPTV's users is gi ven in Table 2.

\subsection{The Study}

The IPTV st udy was im plemented in $80 \mathrm{p}$ ilot schools around $\mathrm{T}$ hailand. S uan Dusit $\mathrm{R}$ ajabaht $\mathrm{U}$ niversity pr ovided free LCD television, set top boxes, and ADSL to the pilot schools. The IPTV system was used by teachers and students in the pilot schools for six months. The research was complied th rough bo th quantitative (a qu estionnaire usi ng $322 \mathrm{sam}$ ples) and qualitative methods (interviews).

Table 2. Demographic profiel of IPTV users.

\begin{tabular}{|c|c|c|c|}
\hline Items & & Frequency & Percent \\
\hline \multirow{5}{*}{ Area } & Central 157 & & 47.29 \\
\hline & Southern 49 & & 14.76 \\
\hline & North 45 & & 13.55 \\
\hline & North-Eastern 71 & & 21.39 \\
\hline & N/A 10 & & 3.01 \\
\hline \multirow{3}{*}{ Gender } & Femal 293 & & 88.25 \\
\hline & Male 37 & & 11.14 \\
\hline & N/A 2 & & 0.60 \\
\hline \multirow{5}{*}{ Age } & $>25$ yrs. & 9 & 2.71 \\
\hline & $26-35$ yrs. & 133 & 40.06 \\
\hline & $36-45$ yrs. & 116 & 34.94 \\
\hline & $<45$ yrs. & 72 & 21.69 \\
\hline & N/A 2 & & 0.60 \\
\hline \multirow{4}{*}{ Education } & Undergraduate 9 & & 2.71 \\
\hline & Bachelor degree & 280 & 84.34 \\
\hline & Master degree/ Ph.D. & 41 & 12.35 \\
\hline & N/A 2 & & 0.60 \\
\hline \multirow{5}{*}{$\begin{array}{c}\text { Work } \\
\text { experience }\end{array}$} & $>1 \mathrm{yr}$ & 6 & 1.81 \\
\hline & $1-5$ yrs. & 98 & 29.52 \\
\hline & $<5$ yrs. & 224 & 67.47 \\
\hline & No experience & 2 & 0.60 \\
\hline & N/A 2 & & 0.60 \\
\hline \multirow{5}{*}{$\begin{array}{c}\text { IT } \\
\text { expereince }\end{array}$} & $>1 \mathrm{yr}$ & 27 & 8.13 \\
\hline & $1-5 \mathrm{yrs}$ & 149 & 44.88 \\
\hline & $<5$ yrs. & 141 & 42.47 \\
\hline & No experience & 13 & 3.92 \\
\hline & N/A 2 & & 0.60 \\
\hline \multirow{5}{*}{$\begin{array}{c}\text { Internet } \\
\text { expereince }\end{array}$} & $>1 \mathrm{yr}$ & 37 & 11.14 \\
\hline & $1-5 \mathrm{yrs}$ & 138 & 41.57 \\
\hline & $<5$ yrs. & 144 & 43.37 \\
\hline & No experience & 11 & 3.31 \\
\hline & N/A 2 & & 0.60 \\
\hline \multirow{3}{*}{$\begin{array}{l}\text { Computer } \\
\text { at school }\end{array}$} & Yes 314 & & 94.58 \\
\hline & No 15 & & 4.52 \\
\hline & N/A 3 & & 0.90 \\
\hline
\end{tabular}

The result of IPTV system evaluation found that most of users used IPTV via set top box (84.34\%) and used IPTV at school 3-4 days per week on average.

The result of user's satisfaction with the IPTV system is shown in Table 3.

The result of the IPTV system evaluation showed that the highest scores ( $\mathrm{m}$ ean $=4.32$ ) were achieved by the television LCD, the ov erall IPTV system (mean $=4.24)$, benefits of using content from IPTV (mean $=4.16$ ), content in IPTV $($ mean $=4.16)$ and set up box $($ mean $=4.04)$ respectively. Here are so me co mments which illu strate the usefulness of the IPTV system as follows:

"I really like IPTV system because it help use to prepare teaching material easier for example I developments program it teach me how to make toys by using plants and natures resources that we can find in our local community. This is very useful for us."

"We can use TV LCD for other purpose as well, such as watching news, connect to the Internet and use for watch IPTV programs."

"I think, content in IPTV is really useful both for teacher and students. Students can learn outside the classroom by using IPTV system. It 's good for education"

The result of IPTV program evaluation show that the highest sc ore were achi eved by Toy s developments $($ means $=4.00)$, Novels $\mathrm{f}$ or $\mathrm{c}$ hildren $(\mathrm{m}$ ean $=3.98)$, Study t ours o utside $t$ he cl ass ro om $($ means $=3.93)$, Teaching and learning at Sa-Tid-La-U-Tid $($ mean $=3.93)$ and English for fun (mean = 3.91), respectively. Here are some co mments illu strate the usefu lness of IPTV programs as follows:

Table 3. User's satisfaction using IPTV system.

\begin{tabular}{lcc}
\hline Issues & Mean & SD \\
\hline IPTV system & & \\
$\mathrm{T} \quad$ elevision LCD & 4.32 & 0.84 \\
Over all IPTV system & 4.24 & 0.72 \\
$\quad$ Benefit of using content from IPTV & 4.16 & 0.77 \\
$\quad$ Content in IPTV & 4.16 & 0.79 \\
$\quad$ Set top box & 4.04 & 0.87 \\
T otal & 4.17 & 0.65 \\
IPTV program & & \\
T oys developments & 4.00 & 0.75 \\
$\quad$ Novels for children & 3.98 & 0.79 \\
$\quad$ Study tours outside the class room & 3.93 & 0.80 \\
$\quad$ Teaching and learning at Sa-Tid-La-U-Tid 3.93 & & 0.80 \\
$\quad$ English for fun & 3.91 & 0.84 \\
T otal & 3.83 & 0.70 \\
\hline
\end{tabular}


"Kids in our school like to watch IPTV program very much especially 'Study tour outside the classroom' program because it help them to explore the world outside the classroom. Children can learn by watching those programs and discuss with their classmates. I think, the IPTV system is very useful especially for teacher and students in the rural areas that can access new knowledge and information for support lifelong learning."

"Kids like to watch English for fun program because our school doesn't have foreigner teachers to teach English. So, I open this program and use for my teaching. Students are really like it."

\section{Conclusion}

The im plication of IPTV 's use in ed ucation was illu strated in this paper. The IPTV project $b$ ackground $w$ as demonstrated and ex plained t hrough I PTV c oncepts, channels $\mathrm{c}$ ontents a nd user $\mathrm{s}$, arc hitecture and devices. The IPTV concepts were design to support distant learning. It consisted of four channels (kids, video on demand, variety an $\mathrm{d}$ ra dio) an $\mathrm{d}$ provided information regarding bandwidth av ailability and it supported a variety of output devices (television monitors, PCs and smart phones). Users can watch IPTV programs b oth in the live and video on demand format. An IPTV st udy was i mplemented in $\mathrm{p}$ ilot scho ols aro und Th ailand. Th e resu $\mathrm{lt}$ found that the IPTV use rs have a high sc ore of sy stem satisfaction and IPTV programs.

\section{Future Work}

The fut ure study should devel op IPTV to mobile IPTV system because the technologi cal trend of $m$ obile IPTV is becoming popul ar and advance. M obile IPTV $t$ echnology is an application that allows users to transmit and receive multimedia content through an IPTV based network with the support of $\mathrm{s}$ ecurity, mobility and interactivity [2]. Also, the research should focus on how to develop learning pedagogy by using IPTV i ntegrated with social networking to support distance learning.

\section{Acknowledgement}

The aut hor would 1 ike to thank y ou the O ffice of Aca- demic Resourc e and In formation Techn ology (AR IT) at Suan Dusit Rajabhat University for pr oviding IPTV systems to the pil ot school s, and pr oviding ne twork infrastructure for supporting IPTV operation.

\section{REFERENCES}

[1] S. Zeadally, and H. M oustafa, "Inter net Pr otocol Television (IPTV): Ar chitecture, Trends, and Challenges, IEEE Systems Journal. Vol.5, No. 4, 2011, pp. 518-527.

[2] P. Suanpang, "T he develop ment I PTV to mobile I PTV implications for teaching and learning", Proeeding of the ICTC 2012 International Conference on ICT Convergence, Korea, 15-17 October 2012, to be published in IE EE Xplo re Digital Library.

[3] A. Al -Hezmi, R. Reb ahi, T . Magedanz and S. Arbanowaski, "Towards an In teractive IP TV for Mobile Subscribers", Proeedina of International Conference on Digital Telecommunications, IEEE Computer Society Press, 2006. doi:10.1109/ICDT.2006.74

[4] Z. Liu, B. Wei, and H. Yu., "IPTV, towards samess infotaiment", Profeeding of $6^{\text {th }}$ IEEE Consumer, Communication, Nework Conference, Japan, 10-13 January 2009, pp.1-5.

[5] T. V. Yuzer and G. Kur uback, "I ntegrating inter net pr otocol television (IPTV ) in distance education: a constructivist framework for soci al networ king", Turkish Online Journal of Distance Education, Vol. 12, No.3, 2011, pp. 259-276.

[6] Mulitmedai Resear ch Group, Inc., “IPTV Golbal For ecast: 2009 to 2013 Semi-Annual IPTV Global Forecast Report".

http://www.international-television.org/tv_market_data/global-ipt v-forecast-2009-2013.html

[7] Budde Co m, “ Thailand - I nternet, B roadband Ser vices, Broadcasting and Forecasts"

http://www.budde.com.au/Research/Thailand-Internet-Broadband -Services-Broadcasting-and-Forecasts.html

[8] J. Chang, C. Lai, Y. Huang, and H. Chao, "3RS: A per sonalized and pop ular program recommend system of digital TV for P2P social networ k", Multimedia T ools Applicate, Vol. 10, No, 1, 2010, pp. 31-48.

[9] E. Martisson, "IPTV the future of television", Report: Computer Communication and Distributed Systems, Chalmers University of Technology.

http://www.cse.chalmers.se/ tsigas/Courses/DCDSeminar/Files/I PTVrapport.pdf

[10] P. Suanpang. "Suan Dusit I nternet T V (SDI B)- Educational Innovation in Kn owledge-Based Society". Special Issue of the International Journal of the Computer, the Internet and Management, Vol. 17, No. SP3, pp, pp. 31.1-31.5,

[11] P. Suanpang, T ermboonpasert. J, Kantam noon. P. and Rengittinun. S. "Internet TV: An Educational Innovation for Developing Teacher in Early Child hood Care Center all over Thailand: Phase 1". SDU Research Journal, Vol. 3, No. 1, 2010, pp. 87-104. 